\title{
EL PODER DE LAS AMAZONAS EN LA LEYENDA DE YURUPARY DE CECILIA CAICEDO
}

\author{
Luisa Ballesteros Rosas \\ Université de Cergy-Pontoise
}

\begin{abstract}
Resumen: En la Leyenda de Yurupary, la escritora colombiana Cecilia Caicedo transmite en forma novelada la rica tradición oral de los pueblos del Vaupés colombo-brasileño, contenida en el Canto de Yurupary escrito en el siglo XIX por el cacique Maximiano José Roberto. Entre mito y realidad, y entre hechos y elementos mágicos, la leyenda expone la existencia del matriarcado, de la religión astral y la imposición tribal del poder masculino a través del héroe civilizador Yurupary al que se enfrentan en una larga lucha encarnizada las mujeres.
\end{abstract}

Palabras clave: Recuperación memoria, Yurupary, amazonas, matriarcado.

Abstract: The Colombian writer Cecilia Caicedo rescuing, promotes and disseminates in her novel Leyenda de Yurupary the cultural traditions of Colombian and Brazilian Indians from Vaupés Amazonian area, knew by the Yurupary song and wrote at first in nengatu language by the Indian boss Maximiano José Roberto in XIX century. It contains ritual performed by some Amazon tribes and concerns their original traditions as the matriarchal system and astral religion before the hero Yurupary imposes the Sun laws which getting away women.

Keywords: Cultural traditions, Yurupary, Amazonian Indians, Women's power.

De los pueblos amazónicos de Suramérica tenemos las primeras noticias por el cronista Fray Gaspar de Carvajal (1504-1584) en su Relación del nuevo descubrimiento del famoso río grande de las Amazonas, nombre que le dio al relacionar la tribu de mujeres que encontró su expedición con el mito griego de las mujeres del Caucazo. Pues las hijas de Ares y de Harmonía también vivían apartadas de los hombres, se dedicaban a la caza y a la guerra y terminaron vencidas por los hombres de Teseo en la guerra con Atenas.

Esta relación del conquistador español no estaba tan errada si nos atenemos a las leyendas de la rica tradición oral del Vaupés colombo-brasileño contenidas en el poema heroico El Canto de Yurupary, que la escritora colombiana Cecilia Caicedo (Pasto, 1945) presenta en una versión novelada con el título explícito 
La leyenda de Yurupary (2003)1. La autora nos pone frente a un fenómeno bastante interesante de reescritura, de traducción y de recuperación de las raíces culturales y de la memoria.

El Canto de Yurupary transmite una de las leyendas más importantes de tradición oral del territorio amazónico desde el periodo prehispánico, que fue propagada en diferentes pueblos y según los investigadores representa un valor semejante al del Popol Vuh maya ${ }^{2}$. El canto fue escrito por primera vez en lengua ñengatú ${ }^{3}$ con caracteres latinos a finales del siglo XIX por el indígena culto Maximiano José Roberto, tuixáua (cacique) de Tarumamiry, descendiente de Manaos y Tarianas. Conocedor de varias lenguas aborígenes, Roberto recorrió por muchos años las tribus amazónicas de Colombia y Brasil en donde existían diversas versiones del mito y constató la evidencia de una religión común en torno al héroe civilizador Yurupary ${ }^{4}$.

Cecilia Caicedo menciona en la introducción el origen de sus fuentes, a comenzar por el Conde italiano Ermanno Stradelli (1852-1926) quien recibió el texto original de la leyenda de manos de Roberto, en el último de sus viajes realizados por el Vaupés entre 1881 y 1891, en los que llevó a cabo una investigación histórica rigurosa sobre la autenticidad y origen del Canto. Fue Stradelli quien lo tradujo primero, en italiano, y lo publicó en 1890 en el Bollettino de la Società Geografica Italiana de Roma ${ }^{5}$; y el naturalista y botánico brasileño Joâo Barbosa Rodrigues (1842-1909) lo tradujo en portugués en 1899. El colombiano Pastor Restrepo Lince hizo, con la asistencia de Américo Carmicelli, la traducción del Canto en español a partir de la versión italiana, y Javier Arango Ferrer se encargó de divulgarla en el tomo XIX de Historia Extensa de Colombia, consagrado al estudio de la literatura nacional ${ }^{6}$, en el que dedica el primer capítulo al periodo aborigen dentro del cual destaca el poema de Yurupary.

Es de notar que la versión de Stradelli fue reproducida en 1964, con otras páginas, en un volumen que editó el Instituto Cultural Italo-Brasileiro de Sâo Paulo $^{7}$. Pero el resumen hecho por Arango Ferrer es la única fuente española de

${ }^{1}$ Caicedo, Cecilia, Leyenda de Yurupary, Bogotá, Cooperativa Editorial Magisterio, 2003.

2 Orjuela, Héctor H., Edición y estudio de Yurupary (El Popol Vuh suramericano) a la traducción española del Canto por Susana N. Salessi, Bogotá, Editorial Kelly, 1993.

${ }^{3}$ La lengua ñengatú, por ser la más hablada, fue impuesta por los misioneros jesuitas del siglo XIX como forma de comunicación entre las tribus amazónicas en donde existe el mito.

${ }^{4}$ Orjuela, Héctor H., Yurupary: mito, leyenda y epopeya del Vaupés, Bogotá, Instituto Caro y Cuervo, 1983, cap. IV, p.71-125.

5 Stradelli, Ermanno, Leggenda dell'Jurupary, Roma, Bollettino de la Società Geografica Italiana, 1890, serie III, vol. III, pp. 659-689, 778-835.

${ }^{6}$ Arango Ferrer, Javier, "Raíz y desarrollo de la literatura colombiana", Historia Extensa de Colombia, Academia Colombiana de Historia, Bogotá, Ediciones Lerner, 1965, tomo XIX, pp.33-42.

7 Stradelli, Ermanno, La leggenda del Jurupary e outras lendas amazónicas, Sau Paulo, Instituto Cultural Italo-Brasileiro de Sâo Paulo, 1964. 
la leyenda hasta finales de 1983 cuando el Instituto Caro y Cuervo publicó la investigación de Héctor H. Orjuela ${ }^{8}$, iniciada en 1981 para su seminario sobre Literatura hispanoamericana en la Universidad de California - Irvine, a la que anexa la traducción de la leyenda en español hecha por su alumna Susana N. Salessi a partir de la traducción italiana basada en el texto ñengatú, que según Orjuela "corresponde, pues, a la versión auténtica y más autorizada del mito amazónico y la única que originalmente fue escrita por un indio"9.

No obstante, Orjuela señala en la introducción la dificultad de acercarse al texto desde el punto de vista poético y literario, ya que los estudios publicados sobre la versión italiana de Stradelli, además de pertenecer al siglo XIX, son de carácter antropológico y etnográfico, con descripciones de viajeros y científicos que han visitado la zona del Vaupés. Esto necesitó llevar a cabo numerosas investigaciones hasta determinar la existencia de Maximiano José Roberto, su genealogía y grandes conocimientos de las costumbres y tradiciones de sus antepasados, como lo prueban las numerosas leyendas que recogió, además de la ayuda que él mismo prestó a muchos investigadores y científicos que vinieron a estudiar los mitos y creencias indígenas.

Con una voluntad evidente de recuperar y transmitir la memoria a través de la ficción histórica, Cecilia Caicedo recoge el contenido y lo estructura en un orden distinto al del Canto, rescatando principalmente el protagonismo de los personajes importantes entre los cuales las mujeres juegan un papel primordial. La autora presenta la columna vertebral de los mitos vehiculados por el Canto del que llama la atención la existencia de un matriarcado "al comienzo del mundo" al que ella hace particular énfasis, así como a las circunstancias que condujeron a la pérdida del poder de las mujeres.

Pero el Canto de Yurupary merece varias lecturas, pues aunque es verdad da particular importancia al nacimiento de algunos personajes femeninos como reproductores de la humanidad y al origen de la religión astral, es difícil darle una orientación feminista dentro del contexto contemporáneo. El canto muestra también los inconvenientes de la falta de hombres en el mundo que describe, y el sufrimiento de las mujeres que se encuentran clasificadas por grupos según su situación (viudas, solteras, viejas, vírgenes), y la evolución de esa situación gracias a la acción de algunos personajes protagónicos con posturas sobrenaturales, que desaparecen y vuelven a aparecer, y apelan en última instancia a sus poderes mágicos (Pinón, Yurupary). También muestra la guerra encarnizada que libran las mujeres a causa de su exclusión dentro de las nuevas normas impuestas, y la profusión de elementos mágicos y hechizos de los hombres para llegar a implantar las leyes de Yurupary, civilizador fuertemente opuesto a las mujeres, y consciente de una misión divina como representante del Sol.

8 Orjuela, Héctor H.,"Yurupary: epopeya indígena suramericana”, Bogotá, Instituto Caro y Cuervo, Thesaurus, 1982, Tomo XXXVII.

${ }^{9}$ Orjuela, 1983, p.129. 
Cecilia Caicedo ejerce en su obra la vulgarización de la leyenda por una recuperación y transmisión de la memoria amazónica, siguiendo las fuentes que emanan de la recolección y trascripción del Canto. La versión novelada de La leyenda de Yurupary se focaliza en la existencia de un pueblo de mujeres que, de acuerdo con la leyenda, en Tunahi tenían un sistema matriarcal, y "debido a que una epidemia había exterminado a los hombres, estaban acompañadas solo por unos ancianos impotentes" 10 . Pero el poema contiene otros tópicos colaterales bastante interesantes que muestran la forma como se produjo el surgimiento del poder tribal masculino entre los grupos amazónicos, con la ayuda de un caudal de elementos mágicos que dificultan distinguir la frontera entre realidad y mito.

El propósito de Cecilia Caicedo es establecer una versión novelada del Canto haciendo el relato desde el origen del hombre a partir de Dinari, una mujer que descontenta del reglamento de su tribu, la abandona y llorando de tristeza se encuentra en la selva con un ilapay, hombre pájaro, con el que forman la pareja que va a dar nacimiento a la religión astral con la figura de Meespuin que se convierte en la constelación Seucy del cielo, protectora de las mujeres, y de su hermano Pinón, primer payé (brujo jefe) poblador del mundo, anunciador de cambios sociales, políticos y culturales importantes que se impondrán a través de su descendiente Yurupary, el engendrado de la fruta.

Sin embargo, la autora resume la acción civilizadora de Yurupary, que fue larga y complicada con una abundancia de acontecimientos mágicos para doblegar la oposición de las mujeres. Al novelar la leyenda, Cecilia Caicedo determina los efectos reales y completa la trama con la ficción que humaniza las anécdotas, haciéndolas más comprensibles.

Repartida en dos partes, con cuatro capítulos cada una, la versión de la escritora colombiana sigue de cerca la esencia del canto indígena, sin entrar mucho en los detalles mágicos que pueden enredar el relato y restarle crédito a causa de la profusión de encantamientos y filtros. En la primera parte despliega la intriga amorosa de la adolescente amazona Dinari, de la tribu Bianaca, quien desea encontrar al hombre de su vida, pero debe aceptar la prioridad de las viudas y mujeres mayores para unirse con uno de los pocos hombres que hay en su tribu. A este personaje femenino rebelde le siguen otros de personalidad fuerte que permite transmitir una moral en cuanto al papel social de las mujeres.

La autora pone en evidencia la simbología benéfica de los elementos naturales, que identifican el Canto de Yurupary con otros textos amerindios náhuatl, mayas y koguis, como el árbol, el viento y el agua. Dinari se acoge a la protección de un árbol hasta que el tuixáua ilapay, joven guerrero de la tribu Iacamy (hombres pájaros) se le acerca conmovido y se enamora de ella: "Se ofreció sin pensarlo dos veces, para que lo acepte como su compañero eterno, como su marido y su cómplice, como su guía y su pareja."11. Ilapay y Dinari se sumergen en las aguas

10 Caicedo, 2003, p. 169.

11 Caicedo, 2003, p. 22. 
sagradas del río Dianumión pero, antes de cruzar, Dinari debe frotarse el cuerpo con unas hierbas machacadas. Al salir los dos a la otra orilla se convierten en lacamy (pájaros) de plumas finas bellísimas.

Los dos hijos engendrados por la pareja, un niño y una niña, nacen con una estrella en el rostro y en los pies, lo cual siembra desconfianza en el espíritu de Ilapay, hasta que el más viejo y sabio de la tribu le explica que Dinari ha sido premiada con la constelación de estrellas que sus dos hijos llevarán para siempre en la frente y en los pies, como muestra de una raza superior. Ilapay regresa a reconciliarse con su mujer y a contemplar a sus hijos pero antes, para sorprenderlos, quiso disfrazarse con sus hombres untándose ceniza. Los niños que habían sido dejados solos por Dinari, y nunca habían visto a sus padres con otra figura que no fuera humana se asustaron. El niño al verlos aproximarse, "se sintió de pronto amenazado y armado de su cauchera procedió a darles muerte"12. Al regreso de Dinari, el niño entusiasmado le muestra el reguero de pájaros muertos y le dice: "Mamá, los maté a todos, eran muchos".

Pero en el Canto, para el niño esto representa un juego y ejercicio de puntería. El niño recogió los pájaros muertos y los amontonó, y fue la sangre que había por todas partes en la casa que dio a Dinari indicios de que algo había ocurrido en su ausencia y se precipitó al cuarto de sus hijos pensando que su marido celoso había regresado para matarlos. Al reconocer a su marido en el montón de pájaros muertos, llora desconsoladamente y trata de explicarle a los niños que el jefe de los pájaros era su padre, lo cual es difícil porque ellos fueron aislados del mundo de los pájaros y Dinari había tenido que volver a cruzar el río par retomar, como ellos, su aspecto humano.

En la novela, Dinari toma a sus hijos de la mano y se va con ellos hacia su tribu de los Bianaca, pero antes de partir, el niño le dice que necesitan un nombre y se pone a él mismo Pinón y a su hermana Meespuin. Pero, según el Canto, la necesidad de tener un nombre se impone al llegar a la tribu de los Bianaca, donde Pinón debe tratar con el jefe y negociar la situación de su madre y de su hermana que temen ser separadas y puestas cada una con las mujeres de su misma situación. Este se impone rápidamente por su fuerza extraordinaria entre los miembros de la tribu de su madre, al desplazar una roca enorme, y, ya joven y hermoso, todas las mujeres quieren hacerse fecundar por él. Diez lunas después, entre los niños que nacen solo hay una niña, Jacy Tata.

La sacralización de las mujeres es iniciada por Pinón por la necesidad de proteger a las mujeres de su familia de las reglas estrictas de los Bianacas con relación al sexo y al amor. Pero en la novela, la sacralización de las mujeres es ya un signo de la pérdida de libertad. Pues Pinón se convierte en jefe de la tribu bianaca y, como su hermana Meespuin comienza a sentir los síntomas de su edad y, la necesidad de un compañero va a ser frustrada por las leyes de la tribu, él "la toma en sus brazos", la lleva al cielo y allí la deja para protegerla del amor

12 Caicedo, 2003, p. 33. 
y de los hombres. "Desde entonces ella se llama Seucy del cielo y vive en lo alto del firmamento"13. Mientras tanto Dinari, la madre de Pinón, desaparece y él se pone a buscarla, pero quiere dejar arreglado lo del futuro de su única hija Jacy Tata, a quien "Decidió tomarla entre sus brazos y antes de que llegara a la edad de los amores, subió por la escalera del cielo y allí la dejó en compañía de Meespuin, la Seucy del cielo.”14. El tuixáua Pinón reparte a sus hombres por los cuatro puntos cardinales para buscar a su madre, Dinari, sin ningún resultado. Insiste, repitiendo a los chasquis (correo oral) la orden para que continúen su búsqueda por todas partes, y él mismo recorre la tierra buscándola, y por donde pasa copula con todas las mujeres que encuentra, convirtiéndose en el primer poblador del mundo, y el padre de la raza humana.

Alguien (en el Canto, Pinón consulta a un brujo) le trae la noticia que Dinari está en el fondo del mar convertida en pez arara y: "Hasta allá bajó Pinón y cuando la encontró subió con ella a la superficie de las aguas, de donde se elevó hasta lo más alto del firmamento" 15 y la dejó allí para que acompañara a su hermana Seucy del cielo, colgadas como dos estrellas, y junto a ellas Jacy Tata, su hija, convertida en una estrella menor.

En la segunda parte de la novela, la autora presenta la fundación del poder masculino. Pues Pinón llega hasta la tribu de los Nunuiba, en donde una epidemia había acabado con los hombres y no había valido ni brujos, ni hierbas, ni sabios. Solas, las mujeres lloraron al principio a sus muertos pero, poco a poco, consientes de su libertad, ríen de todo y de nada todo el tiempo. En la novela estaban felices porque ya "No tenían que cumplir las leyes, no tenían que cocinar, sembrar a horas y días fijos, no tenían que ayudar en la recolección de las cosechas, no tenían que someterse a los golpes del varón que era el marido o el padre"16.

Una de las interdicciones que les imponía la ley a las mujeres era bañarse en el lago de Muypa y, a iniciativa de una joven, todas se metieron al lago donde disfrutaron del agua sagrada. Una de ellas vio en la orilla del lago a un viejo decrépito y, sin que ellas se dieran cuenta, resultó entre ellas en la laguna escuchando que planeaban deshacerse de los pocos ancianos inútiles que quedaban. Al bajar Seucy del cielo a bañarse en el lago sagrado, él le cuenta lo que había escuchado decir a las mujeres. Y finalmente se dirige a ellas para advertirles que, a causa de su desobediencia, Seucy del cielo no volvería a bañarse en el Muypa y por lo tanto ellas perdían su protección. Lo vieron alejarse a pasos cada vez más largos, dejando en el agua un polvo blanco, hasta que recobró su apariencia de joven, pues se había cubierto el cuerpo de polvo para parecer viejo, y subió corriendo a la sierra de Dubá.

13 Caicedo, 2003, p.36.

14 Caicedo, 2003, p.37.

15 Caicedo, 2003, p.43.

16 Caicedo, 2003, p.49. 
Las mujeres salieron sonrientes del agua con esa voz que seguía resonando en sus oídos: "Ahora cada una lleva en las entrañas el germen de la vida"17. En efecto, después de diez lunas, todas parieron asegurando así el futuro de la sierra del Tenuí. El payé joven, disfrazado de viejo, que las había preñado en el agua, no era otro que Pinón, el poblador del mundo, anunciador de los cambios y el nacimiento de un nuevo orden social.

A partir del Canto, la autora aclara las consecuencias de la desobediencia de las mujeres que justifica las leyes en su contra. En efecto, de los hijos de las mujeres desobedientes se alude al nacimiento de una niña hermosa que fue llamada Seucy de la tierra, la cual al crecer, comió por curiosidad las frutas prohibidas del árbol del phycán. Mientras comía, el jugo de la fruta recorría su cuerpo hasta llegar a sus partes íntimas y allí se anidó el líquido maravilloso que dio origen diez lunas después a un bello niño, Yurupary, que significa engendrado de la fruta.

Pronto Yurupary sorprendió a todos por su belleza, la del Sol, su fuerza y su estatura y fue proclamado por los miembros de la comunidad como el nuevo tuixáua (jefe). En su nombramiento intervino Renstalro (la luna), quien le exigió en contrapartida la realización de una misión otorgada por el Sol, que consiste en propagar las leyes, y encontrarle una compañera perfecta en la tierra. Así investido, "Yurupary regresó como ser visible a la tierra, a su espacio, a su tribu, para iniciar a los suyos en las leyes de Yurupary, proponiendo un gobierno de hombres y solo para hombres, del cual serían excluidas para siempre las mujeres."18

En esta parte, otros elementos simbólicos entran en escena, que la autora resalta, dentro de la lucha por la exclusividad de posesión del conocimiento y del poder. La elaboración de los instrumentos y de la música representa el conocimiento, y la elaboración y el uso de las máscaras, signo de las apariencias y de la civilización, representan también al poder político y social de la humanidad. Yurupary convoca primero a los hombres jóvenes, les enseña a fabricar los instrumentos musicales y la música, no sin advertirles que la traición a una de las leyes será castigada con la muerte. Después les indica la necesidad de fabricar las máscaras con cortezas de los árboles sagrados, y los jóvenes observan que cada máscara tiene sus propias características, una figura, un peso de la ley. "Y así fue como cada una de las máscaras quedó lista para ser usada en distintas ceremonias: máscaras para los rituales de la guerra, para las ceremonias sagradas de iniciación sexual, máscaras para hablar con los dioses, máscaras para recordar a los muertos, para la guerra, el amor, el odio, el olvido y también para la iniciación de la cosecha y de las siembras." ${ }^{19}$

17 Caicedo, 2003, p.53.

18 Caicedo, 2003, p.60.

19 Caicedo, 2003, p.69. 
Igualmente, los instrumentos que les enseña a tocar Yurupary producen música para cada ocasión: para llorar a los muertos o a sus amores, y al escuchar su música, todos lloran con tanta intensidad que hasta el mismo Yurupary siente sus lágrimas llenarle los ojos. También les enseñó a construir la maloca (casa) ceremonial en un sitio lejano "que no fuera conocido por las mujeres". Cuando juzgó que ya sus leyes eran de dominio de los hombres, "Yurupary los invitó a llevar su norma por todo el mundo conocido"20.

Pero todo esto era sin contar con la astucia y la curiosidad de las mujeres, que Cecilia Caicedo depura de la infinidad de idas y venidas de los hombres con sus encantamientos. El relato introduce un juego de espionaje realizado por las mujeres quienes llegaron primero a las tribus a donde iba a ser llevada la doctrina y alertaron a las mujeres para que sedujeran a los hombres de Yurupary y descubrieran el secreto. Las de la tribu Nunuiba los reciben con comida y bebidas y les ofrecen unas pócimas especiales que habían preparado para el amor. Las más jóvenes se introducen en las hamacas de los hombres y bajo el efecto de la bebida estos se ponen a hablar sin recato revelando sus secretos. Ualry fue quien más habló, seducido por la joven Diaudué, a quien le reveló donde estaban los instrumentos y las máscaras. Cuando se dio cuenta de su error, se dejó llevar hasta el árbol que tomó su forma y su nombre. En el canto este personaje toma una connotación maligna y es fuente de muchos encantamientos y de desorden.

Así, dentro de un relato fluido, la autora simplifica las anécdotas para contar como las mujeres también realizan un espionaje eficaz para enterarse de la manera como los hombres fabrican y tocan los instrumentos. Presenta el protagonismo de una mujer de la tribu Ariadna, omitiendo muchos detalles del Canto, en el que Curán, la hija del jefe Ariadna es violada durante la fiesta celebrada en honor de Yurupary con quien su padre contaba casarla en cambio de difundir y hacer aplicar sus leyes. Pero Yurupary le impone al violador Caminda casarse con la muchacha. Curán no tiene otro remedio que aceptar, pero se convierte en la principal opositora de las leyes de Yurupary y, a través de Caminda, no solamente descubre el conocimiento de la música sino su máscara y su instrumento musical. En esa lucha encarnizada, Yurupary tiene que apelar varias veces a sus artes de payé (brujo) para neutralizar la acción de las mujeres y al cabo de una lucha ardua termina por ganar la partida, pues Curán y las demás mujeres son vencidas por el representante de las leyes de los hombres.

Sin embargo, el Canto de Yurupary, aparte de mostrar toda una serie de normas sexuales, éticas, religiosas, políticas y sociales bien establecidas que toman un rumbo más estricto y determinado con las leyes de Yurupary excluyendo a las mujeres, paradójicamente da cierto protagonismo al nacimiento de las mujeres. De todos modos éstas son las depositarias de la fecundidad y a través de ellas se preserva la humanidad. Es sobre este poder natural y la rebeldía de las mujeres que la autora de la Leyenda de Yurupary se apoya para realizar una epopeya

${ }^{20}$ Caicedo, 2003, p. 69. 
femenina de lucha contra el patriarcado que las excluye del poder, y lo hace sin mucha dificultad puesto que el Canto le proporciona los elementos.

Pues la primera ley de Yurupary insiste en excluir a las mujeres de todo gobierno y de todo poder, la segunda en la fidelidad a las normas so pena de muerte, la tercera, ligada al saber con exclusividad de los hombres, y la cuarta consiste en la obediencia a Yurupary como representante del Sol y legislador de las leyes de los hombres, y su aplicación obliga a las mujeres a defenderse. Pero las leyes siguientes llevan una función más noble que realza la figura del legislador. Tratan del trabajo armónico, el respeto de la madre tierra, de los animales y las cosas, de honrar a los muertos como a los dioses, y también "hablaban de la paz y la armonía, hablaban de la vida en comunidad transitada por el amor y la solidaridad"21.

La posición de las mujeres llama la atención en la Leyenda de Yurupary pues todas las figuras importantes del mito son transgresoras y, si las leyes de Yurupary fijan las normas sociales y políticas con muestras culturales precisas, la acción rebelde de las mujeres dinamiza el mundo y abren fronteras para el futuro. Así, Dinari, la primera madre mítica que no acepta quedarse sola a la espera de un hombre para casarse, lo busca por su cuenta en el mundo de afuera, y logra unirse con Ilapay. Diaudue desaparece en el agua porque se resiste a vivir en un mundo gobernado solo por hombres. Naruna también muere al querer abandonar a Date y poseer a Yurupary. Igualmente, Seucy de la tierra, madre del héroe, quien comió la fruta prohibida del árbol de Phycán, es convertida en piedra con las otras mujeres que osaron espiar las ceremonias y escuchar la música de los instrumentos sagrados. Pero, Curán, la hija del jefe Ariadna, no solo oyó y aprendió la música y el canto de Yurupary, sino que se prometió recuperar algún día el poder: "y cuando aprendió todos los secretos, volvió a la maloca antes de llegar el día, habiéndose forjado en el corazón un deseo que se prometió cumplir"22.

Tanto en el Canto de Yurupary como en la novela de la escritora colombiana, el héroe civilizador Yurupary no pudo cumplir la totalidad de la misión encargada por el Sol, que era la de extender las leyes entre los pueblos excluyendo a las mujeres y encontrarle al Sol una compañera perfecta en la tierra.

Con su novela, Cecilia Caicedo responde a las exigencias de la literatura femenina de América Latina de estos últimos años que es la de recobrar las raíces culturales, recuperar la memoria y darle voz propia a la mujer, situándola en el lugar que le corresponde en la historia. Y el Canto de Yurupary es la fuente perfecta para restablecer el discurso vigente y cuestionarse sobre la relación de los sexos y la lucha de dominación o de emancipación, que para los protagonistas Curán y Yurupary sigue inconclusa pero nos lanza muchos interrogantes.

21 Caicedo, 2003, p. 67

22 Caicedo, 2003, p. 91. 


\section{BIBLIOGRAFÍA}

Arango, Javier, Arango Ferrer, Javier, "Raíz y desarrollo de la literatura colombiana”, Historia Extensa de Colombia, Academia Colombiana de Historia, Bogotá, Ediciones Lerner, 1965.

Barbosa Rodrígues, Joâo, "Poranduba amazonense", Anais de Biblioteca Nacional, Río de Janeiro, 1986.

Caicedo, Cecilia, Leyenda de Yurupary, Bogotá, Cooperativa Editorial Magisterio, 2003.

-, Origen de la literatura colombiana, Yurupary, Pereira, Universidad Tecnológica de Pereira, 1990, Bogotá, Norma, 1990.

Orjuela, Héctor H., "Yurupary: epopeya indígena suramericana”, Bogotá, Instituto Caro y Cuervo, Thesaurus, 1982.

-, Yurupary: Mito, leyenda y epopeya del Vaupés, Bogotá, Instituto Caro y Cuervo, 1983.

-,Yurupary. El Popol Vuh suramericano. Edición y estudio a la traducción española de Susana N. Salessi, Bogotá, Editorial Kelly, 1993.

Stradelli, Ermanno, Leggenda dell'Jurupary, Roma, Bollettino de la Società Geografica Italiana, 1890.

—, La leggenda del Jurupary e outras lendas amazónicas, Sâo Paulo, Instituto Cultural Italo-Brasileiro de Sâo Paulo, 1963.

Nombre del autor: Luisa Ballesteros Rosas

Dirección-e: luisa.ballesteros@free.fr

Dirección postal: $\quad 108$, Avenue des Ternes

75017 Paris, France

Fecha de recepción: $02 / 02 / 2013$

Fechade aceptación: 30/04/2014 